\title{
Prevalence and Factors Associated with Anxiety and Depression Amongst Hospitalised COVID-19 patients in Laquintinie Hospital Douala, Cameroon
}

Stewart Ndutard Ngasa ( $\sim$ stewart.ndutard3@gmail.com )

Medical Research and Careers Organisation https://orcid.org/0000-0001-5954-9717

Leticia Armelle Sani Tchouda

Medical Research and Careers Organisation

Christabel Abanda

Medical Research and Careers Organisation

Neh Chang Ngasa

Medical Research and Careers Organisation

Eric Wah Sanji1

Medical Research and Careers Organisation

Therence Nwana Dingana1

Medical Research and Careers Organisation

Carlson-Sama Babila

Medical Research and Careers Organisation

\section{Research Article}

Keywords: COVID-19, Anxiety, Depression, Psychotherapy, Cameroon

Posted Date: September 16th, 2021

DOl: https://doi.org/10.21203/rs.3.rs-871529/v1

License: (9) (i) This work is licensed under a Creative Commons Attribution 4.0 International License.

Read Full License

Version of Record: A version of this preprint was published at PLOS ONE on December 2nd, 2021. See the published version at https://doi.org/10.1371/journal.pone.0260819. 


\section{Abstract}

Introduction: Studies assessing the mental health of patients with COVID-19 infection remain limited. Disasters and major emergencies, not just COVID-19, undoubtedly lead to greater incidence of mental health problems. Previous studies indicate that the novel Coronavirus disease can cause panic and stress in patients. Our literature search didn't reveal any previous published data from Cameroon and the Central African sub-region. In order to bridge this gap, we assessed the prevalence and factors associated with depression and anxiety in COVID-19 patients.

Methods: We carried out a cross-sectional study in a secondary hospital in the Littoral Region of Cameroon. We recruited hospitalised COVID-19 patients during a 4-month period. We collected data on sociodemographic characteristics. The HADS score was used to assess levels of anxiety and depression. All analysis were done using Stata 14 . A P value of $<0.05$ was used as the cut-off for statistical significance.

Results: A total number of 285 patients took part in this study with a mean age of 48.47 years. The prevalence of anxiety in COVID-19 patients was $60.35 \%$ while the prevalence of depression was $81.40 \%$. At multivariate logistic regression male gender (OR: 1.89, $\mathrm{P}=0.04$ ), hypoxaemia (OR: $2.20, \mathrm{P}=0.01$ ), presence of COVID-19 complications (OR: 1.61, $\mathrm{P}=0.02$ ) and current episode of depression (OR: 4.14, $P<0.01)$ were independently associated with anxiety. Similarly, age $>35$ years $(O R: 2.03, P=0.02)$, presence of comorbidity (OR: $1.68, \mathrm{P}=0.01$ ), $\mathrm{BMI}>=30 \mathrm{~kg} / \mathrm{m} 2$ (OR: $1.78, \mathrm{P}=0.02$ ), presence of COVID-19 complications (OR: 1.28, $\mathrm{P}=0.01$ ) and anxiety (OR: 4.60, $\mathrm{P}<0.001)$ were independently associated with depression.

Conclusion: Hospitalised patients with COVID-19 experienced high levels of anxiety and depression. Treatment of hospitalised patients with COVID-19 should therefore include psychotherapy and psychiatric support.

\section{Introduction}

By the end of 2019, a group of patients presenting with signs and symptoms of acute respiratory compromise and idiopathic pneumonia were reported in Wuhan, China. As the cases built up in numbers, the disease was subsequently confirmed to be caused by a novel strain of the Coronavirus and named 2019-nCoV (Covid-19)[1]. Thereon, it rapidly spread throughout the globe; one month after patient zero, the World Health Organisation (WHO) declared it a public health emergency of international concern and 03 months later, it was declared a pandemic[2]. COVID-19 is a life-threatening infectious disease with about 209,201,939 confirmed cases and 4,390,467 deaths recorded globally as of August 2021[3]. In Cameroon, the first case of Covid-19 was confirmed and isolated on the 06th March 2020 [3] and so far, the country has experienced a steady rise in cases till date; currently 61731 cases and 919 deaths [4].

Though the true impact of Covid-19 cannot be overemphasised, insights regarding the psychological burden beyond the clinical outcomes can also not be ignored as we have learned from prior viral 
infections with similar pandemic potentials; severe acute respiratory syndrome (SARS) and Middle East respiratory syndrome (MERS) being the more recent examples (2002 and 2012)[5]. Other than the associated considerable morbidity/mortality, prior studies on these highly transmissible infections reported a range of adverse psychological disturbances including but not limited to stress, fear, anxiety, depression, insomnia, sadness, Post-traumatic stress disorder (PTSD) $[6,7]$.

Given the overwhelming mortality of Covid-19 (more deaths recorded than from SARS and MERS combined)[8], measures to contain its continual spread such as social and physical distancing (selfisolation, quarantines, lockdowns), travel restrictions, as well as information overload in the media were put in place. These comes with numerous substantial socio-economic and cultural challenges which could trigger or further worsen mental health status. However, most studies assessing the psychological impact of the pandemic have mostly been focused on the general public [9], healthcare workers [10-12], students [13], amongst others.

A few studies have demonstrated high prevalence of anxiety and depression among hospitalised Covid19 patients. In a study carried out in the United States the prevalence of anxiety and depression among these patients were $34.72 \%$ and $28.14 \%$ respectively [14]. In a similar study carried out in China, $18.6 \%$ of Covid-19 patients were anxious and $13.4 \%$ were depressed [15]. While in Nigeria a prevalence of $27.5 \%$ and $28.1 \%$ were reported for anxiety and depression respectively among Covid-19 patients [16]. Despite these evidence of significant mental distress amongst affected patients, there is a paucity of related data in Cameroon, a country with a growing burden of the disease and a reported low vaccine uptake rates[17] We therefore sort to assess the prevalence of anxiety and depression as well as its associated factors among hospitalised Covid-19 patients at Laquintinie Hospital Douala, Cameroon. This study can reveal valuable depths into the problem and thus help provide a tailored and holistic approach in the management of these patients and hence improve acute outcomes and long-term prognosis.

\section{Methods}

\section{Study design, setting and participants}

We conducted a cross-sectional hospital-based study from April to July 2021 in the Laquintinie Hospital, Douala, Cameroon. The outbreak of COVID-19 let to the construction of isolation units with a capacity of more than 60 beds. These units had 2 doctors and 4 nurses for each shift. Any patient with a confirmed COVID-19 positive test by RDT and/or PCR received a post-test counselling. These patients were then admitted into the isolation units and were treated according to the national protocol for the treatment of COVID-19 as prescribed by the Ministry of Public Health of Cameroon.

\section{Sampling and data collection}


A consecutive convenience sampling technique was used to recruit eligible participants into the study. We pre-tested our questionnaire on a group of 10 patients prior to the commencement of data collection. The patients who took part in the pre-test were excluded from the study. All poorly filled questionnaires were not included in the final analysis.

\section{Outcome variables}

Our main outcomes were hospital anxiety and depression. These were assessed using the Hospital Anxiety and Depression Scale (HADS). The HADS has been used extensively to measure anxiety and depression in clinical settings. Several review studies have indicated that it has adequate internal, interrater, and retest reliability; and convergent, discriminant, and predictive validity[18]. This scale has 14 items with half pertaining to anxiety and half to depression. Each item is scored on a four-point scale ranging from 0 to 3 , giving a maximum score of 21 for each subscale. A score of 7 or less is considered normal; scores of 8-10 represent "borderline" and scores of 11 or more indicate the presence of anxiety or depression depending on the relevant subscale[18].

\section{Independent variables}

The following variables were evaluated for association with hospital anxiety and depression: marital status(Single/Divorce, Married), gender (Male, Female), age(years), occupation(Employed and Unemployed), household number, setting (urban or rural), religious denomination (Muslim, Christian, atheists and others); BMI(kg/m2); Number of days of admission; level of education; Presence of comorbidities; Past history of depression and other mental health illnesses; Alcohol consumption; Cigarette smoking; Recent major life event; Presence of COVID-19 complications; COVID-19 Vaccination status; Other family members infected with COVID-19 and Oxygen saturation levels.

\section{Sample size calculation}

The sample size was obtained using the formula for estimation of a proportion since our major outcome was prevalence of hospital anxiety and depression.

$$
n=\frac{\left[4(\text { Zcrit })^{2} \mathrm{p}(1-\mathrm{P})\right]}{\mathrm{D}^{2}}
$$

Where,

$\mathrm{n}=$ Number of participants

$Z_{\text {crit }}=$ the standard normal deviation, corresponding to a significance criterion of $0.05(95),=1.960$

$D=$ Amount of error we will tolerate $= \pm 6 \%$ 
$P=$ Pre-study estimate of the prevalence of covid 19 vaccine acceptance in health workers $=60 \%$

A pre-estimate value of $\mathrm{P}=40 \%$ was used. This was in accordance to a similar study in Marrakech, Morocco, where about $40 \%$ of hospitalised COVID-19 patients presented with symptoms of depression [19].

$$
\begin{aligned}
& \mathrm{n}=\frac{\left[4(1.960)^{2} 0.4 * 0.6\right]}{(0.12)^{2}} \\
& \mathrm{n}=256 \text { COVID-19 patients. }
\end{aligned}
$$

\section{Statistical methods and data analysis}

Data were entered into excel spreadsheet and analysed using Stata version 14 statistical software. Results were presented as means and standard deviation (SD) for continuous variables and frequencies and percentages for categorical variables. At bivariate analysis, we used the Cochran-Mantel-Haenszel test to obtain crudes Odd Ratios (OR) of factors associated with hospital anxiety and depression. Multivariate logistic regression was used to identify independent associations with hospital anxiety and depression. This was presented as adjusted odd ratios along with their $p$-values. A p-value of $<0.05$ was used as cut off for statistical significance.

\section{Results}

\section{Sociodemographic characteristics of participants}

A total number of 285 patients took part in this study with a mean age of $48.47 \pm 16.01$ years and mean BMl of $25.10 \pm 4.15 \mathrm{~kg} / \mathrm{m} 2$. The mean number of days of admission for all participants was $5.10 \pm 2.52$ days. More than two-thirds (67.72\%) of participants were male. Majority of the participants were employed (64.56\%) and married (62.46\%). Almost all participants were Christians (98.25\%), without history of other mental health condition (90.53\%) and had not received a COVID-19 vaccine $(99.30 \%)$. The presence of comorbidity was reported by $20.70 \%$ of participants (table 1 ). Diabetes Mellitus was the most common comorbidity (Figure 1).

\section{Table 1: Sociodemographic characteristics of Participants}




\begin{tabular}{|c|c|c|}
\hline Variables & \multicolumn{2}{|c|}{ Mean \pm SD } \\
\hline Age(years) & \multicolumn{2}{|c|}{$48.47 \pm 16.01$} \\
\hline BMI(Kg/m2) & \multicolumn{2}{|c|}{$25.10 \pm 4.15$} \\
\hline Admission days & \multicolumn{2}{|c|}{ 5.10_2.52 } \\
\hline Oxygen saturation (\%) & \multicolumn{2}{|c|}{$80 \pm 9.86$} \\
\hline Anxiety score & \multicolumn{2}{|c|}{$11.36 \pm 2.28$} \\
\hline \multirow[t]{2}{*}{ Depression score } & \multicolumn{2}{|c|}{$12.80 \pm 2.40$} \\
\hline & $\mathbf{N}$ & Percentage (\%) \\
\hline \multicolumn{3}{|l|}{ Gender } \\
\hline Male & 193 & 67.72 \\
\hline Female & 92 & 32.28 \\
\hline \multicolumn{3}{|l|}{ Employment Status } \\
\hline Unemployed & 101 & 35.44 \\
\hline Employed & 184 & 64.56 \\
\hline \multicolumn{3}{|l|}{ Education } \\
\hline Primary & 59 & 20.70 \\
\hline Secondary & 94 & 32.98 \\
\hline Tertiary & 132 & 46.32 \\
\hline \multicolumn{3}{|l|}{ Marital Status } \\
\hline Single/ Divorced & 107 & 37.48 \\
\hline Married & 178 & 62.46 \\
\hline \multicolumn{3}{|l|}{ Religion } \\
\hline Muslim & 5 & 1.75 \\
\hline Christians & 280 & 98.25 \\
\hline Others & 0 & 0 \\
\hline \multicolumn{3}{|l|}{ Presence of comorbidity } \\
\hline Present & 59 & 20.70 \\
\hline Absent & 226 & 79.30 \\
\hline History of depression & & \\
\hline
\end{tabular}




\begin{tabular}{|lll|}
\hline Yes & 56 & 19.65 \\
\hline No & 229 & 80.35 \\
\hline Yes & & \\
\hline No & 27 & 9.47 \\
\hline Consumes alcohol & 258 & 90.53 \\
\hline Yes & & \\
\hline No & 257 & 90.18 \\
\hline Vaccination status & 28 & 9.82 \\
\hline Vaccinated & & \\
\hline Not vaccinated & 2 & 0.70 \\
\hline Infected family members & 283 & 99.30 \\
\hline Yes & & \\
\hline No & 54 & 18.95 \\
\hline
\end{tabular}

\section{Prevalence of Anxiety and Depression}

The mean anxiety and depression scores were $11.36 \pm 2.28$ and $12.80 \pm 2.40$ respectively. The prevalence of anxiety in COVID-19 patients was $60.35 \%$ while the prevalence of depression was $81.40 \%$ (Figure 2).

\section{Factors associated with depression}

At bivariate analysis, age $>35$ years (OR:2.56, $\mathrm{P}=0.002)$, presence of comorbidity (OR:1.59, $\mathrm{P}<001)$, obesity (OR: $2.70, P<0.001)$, being employed (OR:1.83, $P=0.04)$, hypoxaemia $(\mathrm{OR}: 2.94,0.002)$, presence of COVID-19 complications (OR: 1.72, $\mathrm{P}=0.001$ ) and anxiety (OR: $5.96, \mathrm{P}<0.001$ ) were associated to depression (Table 2).

The following variables were independently associated with depression: age $>35$ years (OR:2.03, $\mathrm{P}=$ $0.02)$, presence of comorbidity (OR: $1.68, P=0.01), B M I>=30 \mathrm{~kg} / \mathrm{m} 2$ (OR: $1.78, P=0.02)$, presence of COVID-19 complications (OR: 1.28, $\mathrm{P}=0.01$ ) and anxiety (OR: 4.60, $\mathrm{P}<0.001)$ (Table 2).

\section{Table 2: Factors associated with Depression}




\begin{tabular}{|c|c|c|c|c|c|}
\hline Variables & & $\begin{array}{l}\text { Crude } \\
\text { ORs }\end{array}$ & $\begin{array}{l}\mathrm{P}- \\
\text { value }\end{array}$ & $\begin{array}{l}\text { Adjusted } \\
\text { OR }\end{array}$ & $\begin{array}{l}\mathrm{P}- \\
\text { value }\end{array}$ \\
\hline \multirow[t]{2}{*}{ Marital status } & Married & 1.31 & 0.25 & * & * \\
\hline & Single/Divorce & 1 & & & \\
\hline \multirow[t]{2}{*}{ Gender } & Male & 1.64 & 0.10 & 1.0 & 0.96 \\
\hline & Female & 1 & & & \\
\hline \multirow[t]{2}{*}{ Age group } & $>35$ & 2.56 & 0.002 & 2.03 & 0.02 \\
\hline & $<=35$ & 1 & & & \\
\hline \multirow[t]{2}{*}{ Presence of comorbidity } & Yes & 1.59 & $<0.001$ & 1.68 & 0.01 \\
\hline & No & 1 & & & \\
\hline \multirow[t]{2}{*}{ BMI } & $\begin{array}{l}\text { Obesity } \\
(=>30 \mathrm{~kg} / \mathrm{m} 2)\end{array}$ & 2.70 & $<0.001$ & 1.78 & 0.002 \\
\hline & $<30 \mathrm{~kg} / \mathrm{m} 2$ & 1 & & & \\
\hline \multirow[t]{2}{*}{ Level of education } & University & 1.31 & 0.07 & * & * \\
\hline & Primary/Secondary & 1 & & & \\
\hline \multirow[t]{2}{*}{ Employment status } & Employed & 1.83 & 0.04 & 1.20 & 0.60 \\
\hline & Unemployed & 1 & & & \\
\hline \multirow[t]{2}{*}{ Days of hospitalisation } & $>=5$ days & 1.29 & 0.53 & * & * \\
\hline & $<5$ days & 1 & & & \\
\hline \multirow[t]{2}{*}{ Oxygen saturation } & Hypoxaemia $(<80)$ & 2.94 & 0.002 & 2.14 & 0.07 \\
\hline & $>=80$ & 1 & & 1 & \\
\hline \multirow[t]{2}{*}{ Alcohol consumption } & Yes & 1.30 & 0.54 & 1.01 & 0.90 \\
\hline & No & 1 & & & \\
\hline \multirow[t]{2}{*}{ Smoking } & Yes & 1.24 & 0.49 & * & * \\
\hline & No & 1 & & & \\
\hline \multirow{2}{*}{$\begin{array}{l}\text { History of mental health } \\
\text { condition }\end{array}$} & Yes & 1.92 & 0.20 & * & * \\
\hline & No & 1 & & & \\
\hline \multirow[t]{2}{*}{ History of depression } & Yes & 1.60 & 0.08 & * & * \\
\hline & No & 1 & & & \\
\hline $\begin{array}{l}\text { Presence of COVID-19 } \\
\text { complications }\end{array}$ & Yes & 1.72 & 0.001 & 1.28 & 0.013 \\
\hline
\end{tabular}




\begin{tabular}{|llllll|} 
& No & 1 & & 1 & \\
Presence of family support & Yes & 1.49 & 0.25 & $*$ & $*$ \\
\cline { 2 - 5 } & No & 1 & & & \\
\hline Anxiety & Yes & 5.95 & $<0.001$ & 4.60 & $<0.001$ \\
& No & 1 & & 1 & \\
\hline
\end{tabular}

*Excluded in the multivariate logistic regression model

\section{Factors associated with anxiety}

Crudes associates of anxiety identified in this study included, being married (OR: 1.55, $\mathrm{P}=0.02$ ), being a male patient (OR: 2.29, $\mathrm{P}=0.001)$, age $>35$ (OR: 2.59, $\mathrm{P}=0.003$ ), obtaining at least a university education (OR: 1.28, $P=0.04$ ), hypoxaemia (OR:2.89, $P<0.001$ ), history of depression (OR: $1.63, P=0.001$ ), presence of COVI-19 complications (OR:1.73, $\mathrm{P}<0.001)$ and current depressive episode (OR: 5.96, $\mathrm{P}<0.001)$ (Table $3)$.

At multivariate logistic regression male gender (OR: 1.89, $\mathrm{P}=0.04$ ), hypoxaemia (OR: 2.20, $\mathrm{P}=0.01$ ), presence of COVID-19 complications (OR: 1.61, $\mathrm{P}=0.02$ ) and current episode of depression (OR: 4.14, $\mathrm{P}<0.01$ ) were independently associated with anxiety (Table 3 ).

\section{Table 3: Factors associated with Anxiety}




\begin{tabular}{|c|c|c|c|c|c|}
\hline Variables & & $\begin{array}{l}\text { Crude } \\
\text { ORs }\end{array}$ & $\begin{array}{l}P \text { - } \\
\text { value }\end{array}$ & $\begin{array}{l}\text { Adjusted } \\
\text { OR }\end{array}$ & $\begin{array}{l}\text { P- } \\
\text { value }\end{array}$ \\
\hline \multirow[t]{2}{*}{ Marital status } & Married & 1.55 & 0.02 & 1.43 & 0.11 \\
\hline & \multicolumn{5}{|l|}{ Single/Divorce } \\
\hline \multirow[t]{2}{*}{ Gender } & Male & 2.29 & 0.001 & 1.89 & 0.04 \\
\hline & \multicolumn{5}{|l|}{ Female } \\
\hline \multirow[t]{2}{*}{ Age group } & $>35$ & 2.59 & 0.003 & 1.48 & 0.23 \\
\hline & $<=35$ & 1 & & & \\
\hline \multirow[t]{2}{*}{ Presence of comorbidity } & Yes & 1.1 & 0.86 & * & * \\
\hline & No & & & & \\
\hline \multirow[t]{2}{*}{ BMI } & Obesity (BMI > 35) & 1.29 & 0.29 & * & * \\
\hline & $\mathrm{BMI}<35 \mathrm{~kg} / \mathrm{m} 2$ & 1 & & & \\
\hline \multirow[t]{2}{*}{ Education } & University & 1.28 & 0.04 & 1.16 & 0.40 \\
\hline & Primary/Secondary & 1 & & & \\
\hline \multirow[t]{2}{*}{ Employment status } & Employed & 1.65 & 0.04 & 1.30 & 0.40 \\
\hline & Unemployed & & & & \\
\hline \multirow[t]{2}{*}{ Days of hospitalisation } & $>=5$ days & 1.16 & 0.53 & * & * \\
\hline & $<5$ days & 1 & & & \\
\hline \multirow[t]{2}{*}{ Oxygen saturation } & $<80$ & 2.89 & $<0.001$ & 2.20 & 0.01 \\
\hline & $>=80$ & 1 & & & \\
\hline \multirow[t]{2}{*}{ Alcohol consumption } & Yes & 1.87 & 0.11 & * & * \\
\hline & No & & & & \\
\hline \multirow[t]{2}{*}{ Smoker } & Yes & 1.09 & 0.78 & * & * \\
\hline & No & & & & \\
\hline \multirow{2}{*}{$\begin{array}{l}\text { History of mental health } \\
\text { condition }\end{array}$} & Yes & 2.40 & 0.05 & * & * \\
\hline & No & & & & \\
\hline \multirow[t]{2}{*}{ History of depression } & Yes & 1.63 & 0.001 & 1.49 & 0.20 \\
\hline & No & & & & \\
\hline Presence of Life event & Yes & 1.33 & 0.40 & * & * \\
\hline Presence of COVID-19 & Yes & 1.73 & $<0.001$ & 1.61 & 0.02 \\
\hline
\end{tabular}

Page 10/18 


\begin{tabular}{|l|lllll|}
\cline { 2 - 5 } complications & No & & & & \\
Presence of family support & Yes & 0.60 & 0.10 & $*$ & $*$ \\
\hline No & No & & & & \\
\hline Yes & 5.95 & $<0.001$ & 4.14 & $<0.001$ \\
\hline & No & & & & \\
\hline
\end{tabular}

*Excluded in the multivariate logistic regression model

\section{Discussion}

Given the increasing rates/burden of mental illnesses globally, the need to assess the psychological impact of COVID-19 is crucial; particularly amongst hospitalised patients of black origin who disproportionately suffer more adverse outcomes than other demographics[20,21]. Such outcomes maybe further compounded in resource-limited settings where the burden of unmet psychological needs is higher. However, data defining the scale of the problem in these settings is scarce as reflected in a recent meta-analysis[22] wherein study findings were limited by lack of data within the African region. It is with this backdrop that we assessed the level of anxiety and depression as well as their associated factors in COVID-19 patients admitted at a second category hospital in Cameroon. Our study demonstrated that about two-thirds of patients (60.35\%) presented with anxiety while more than $80 \%$ of them presented with depression. These results were two to four times higher than those previously reported in other cross-sectional studies [14-16]. Our findings also mirror that of a systematic review conducted by Wu et al [23] which reported a high prevalence of a range of mental health problems (anxiety and depression inclusive) resulting from the COVID-19 pandemic [23].

In an online survey of COVID-19 patients in Nigeria, $27.5 \%$ and $28.1 \%$ of respondents presented with anxiety and depression respectively [16]. The lower prevalence of anxiety and depression reported in their study could be due to the fact that they recruited everyone who had tested positive for COVID-19. In our study we included only hospitalised patients with severe COVID-19 infections. Having a cohort of sicker patients in our study might have let to the increase level of anxiety and depression. In a similar study in Wuhan, $18.6 \%$ of participants experienced anxiety symptoms while $13.4 \%$ experienced depressive symptoms [15]. The Wuhan study had a smaller study population and was carried earlier on during the pandemic, when there was limited information on the lethality of the virus.

Despite the varying methodological approaches employed by these studies and limitations faced, the overall evidence still suggests that the pooled prevalence of psychological disturbances (anxiety, depression, stress, sleep problems) during the COVID-19 pandemic is significantly higher than prepandemic levels[22]. It is also worth mentioning that such high levels of psychological disturbance have been shown to persist beyond the acute phase with some studies finding up to $35 \%$ of patients with residual anxiety and depression months post-hospitalisation with a virus of similar pandemic 
potentials [24]. Thus, if trends were to continue, the attention this deserves from the relevant authorities cannot be underestimated.

A number of factors have been shown to be associated with anxiety and depression. Independent risk factors for anxiety identified in our study included: hypoxaemia, male gender, presence of COVID-19 complications, and comorbid depression. These findings have been corroborated in previous studies where it has been demonstrated patients with low oxygen saturation levels were more likely to be anxious $[19,25]$. It has been postulated that the increase anxiety might not just be linked to the physical stress of the illness but also to the side effects of the treatment given to patients [19]. We also found that male patients were at higher risk of anxiety. This finding contradicts those of previous studies which demonstrated that females were more likely to develop mood disorders and stress-related mental illness including depression and anxiety [14,19]. Finally, the observed association of high levels of anxiety with COVID-19 complications and comorbid depression has been demonstrated in a study by Mazza et al. [26]. In their study, it was postulated that increase levels anxiety and depression as a long-term sequela of COVID-19 infection could be explained by the inflammatory changes cause by the infection.

Independent risk factors for depression included: age > 35 years, presence of comorbidity, obese patients, the presence of COVID-19 complications and comorbid anxiety. It has been shown that older patients were more likely to be depressed [19]. Also, another study revealed that the presence of other comorbidity was associated with higher levels of depression [16]. Our study also showed a strong evidence of an association between obesity and depression in COVID-19 patients. Obesity is on the rise, it is now a second pandemic running parallel to the COVID-19 pandemic [27]. It has been demonstrated that obesity has a strong positive correlation with depression leading to fatal outcomes in COVID-19 patients [28]. Physical activity is beneficial to mental health and immunity. Encouraging and helping individuals to be physically active during the COVID-19 pandemic could reduce the risk of depression and other mental health problems. Anxiety and depression usually co-exist in many people suffering from mental health conditions. This co-existence has been demonstrated in patients with COVID-19 infection during the acute infection(as demonstrated in our study), and as a long term sequelae of the disease[26].

\section{Strengths and limitations}

There were several strengths to this study: to the best of our knowledge, this was the first study to assess levels of anxiety and depression amongst hospitalised COVID-19 patients in Cameroon. We also included a larger sample size compared to the previous studies we identified in the literature search. Finally, a consecutive random sampling method was used to recruit patients into the study. This helped minimize selection bias in our study.

There were however some limitations to our study:

We recruited patients from a single COVID-19 treatment centre in Cameroon. Thus, it might be misleading to generalise the findings to the entire country or sub-region. Also, most of the data were self-reported by 
the recruited patients, some of them in distress at the time of data collection. This can lead to high level of recall bias. Further, the snapshot study design implies causality cannot be inferred.

Regardless, being a pioneer study within the country, the findings have implications for healthcare providers and policy makers as it underlines the high rates of mental health issues among hospitalised Covid-19 patients. Furthermore, not only does the data sets the foundation for future studies; it also underpins the importance of a holistic approach in managing these patients, taking into account both the clinical and phycological aspects. This might be invaluable in the prevention of adverse short- and longterm outcomes.

\section{Conclusion}

The results demonstrated that hospitalised patients with COVID-19 experienced high levels anxiety and depression. Anxiety was associated with male gender, hypoxaemia, presence of COVID-19 complications and comorbid depression while depression was associated with age $>35$ years, presence of comorbidity, obesity, the presence of COVID-19 complications and comorbid anxiety. Therefore, psychological and psychiatric support should be an integral part in the management of these patients.

\section{Declarations}

\section{Acknowledgement}

Our sincere gratitude goes to all the healthcare workers who volunteered to take part in this survey and are spending long hours taking care of COVID-19 patients in Cameroon. Our sincere gratitude goes to Pride Yanu for taking time to proofread this entire work.

A statement of ethics approval- Ethical approval was obtained from the Ethical Review Board of the Bamenda Regional Hospital. Competing interests: The authors declare no competing interests.

\section{References}

1. COVID-19 vaccine tracker and landscape [Internet]. [cited 2021 Jun 29]. Available from: https://www.who.int/publications/m/item/draft-landscape-of-covid-19-candidate-vaccines

2. Fauci AS, Lane HC, Redfield RR. Covid-19 - Navigating the Uncharted. https://doi.org/101056/NEJMe2002387 [Internet]. 2020 Feb 28 [cited 2021 Aug 22];382(13):1268-9. Available from: https://www.nejm.org/doi/full/10.1056/nejme2002387

3. Geneva. Prevention of Mental Disorders Effective Interventions And Policy Options Summary Report World Health Organization Prevention Of Mental Disorders Effective Interventions And Policy Options Summary Report. [cited 2018 May 18]; Available from:

http://www.who.int/mental_health/evidence/en/prevention_of_mental_disorders_sr.pdf 
4. Health M of P. Epidémie de Coronavirus (COVID - 19) I MINSANTE [Internet]. [cited 2021 Aug 22]. Available from: https://www.minsante.cm/site/?q=fr/epid-mie-de-coronavirus-covid--19-

5. Hyun-Chung K, So-Young Y, Bun-Hee L, So L, Hyoung-Shik S. Psychiatric Findings in Suspected and Confirmed Middle East Respiratory Syndrome Patients Quarantined in Hospital: A Retrospective Chart Analysis. Psychiatry Investig [Internet]. 2018 Apr 1 [cited 2021 Aug 22];15(4):355-60. Available from: https://pubmed.ncbi.nlm.nih.gov/29593206/

6. Li G qiang, Zhang $Y$ hua. [Clinical features of 77 patients with severe acute respiratory syndrome]. Chinese Crit care Med [Internet]. 2003 [cited 2021 Aug 22];15(7):404-7. Available from: https://pubmed.ncbi.nlm.nih.gov/12857492/

7. Sheng B, Cheng SKW, Lau KK, Li HL, Chan ELY. The effects of disease severity, use of corticosteroids and social factors on neuropsychiatric complaints in severe acute respiratory syndrome (SARS) patients at acute and convalescent phases. Eur Psychiatry [Internet]. 2005 [cited 2021 Aug 22];20(3):236. Available from: /pmc/articles/PMC7135192/

8. Mahase E. Coronavirus: covid-19 has killed more people than SARS and MERS combined, despite lower case fatality rate. BMJ [Internet]. 2020 Feb 18 [cited 2021 Aug 22];368:m641. Available from: https://www.bmj.com/content/368/bmj.m641

9. Wang C, Pan R, Wan X, Tan Y, Xu L, Ho CS, et al. Immediate Psychological Responses and Associated Factors during the Initial Stage of the 2019 Coronavirus Disease (COVID-19) Epidemic among the General Population in China. Int J Environ Res Public Health [Internet]. 2020 Mar 1 [cited 2021 Aug 22];17(5):1729. Available from: /pmc/articles/PMC7084952/

10. Tasnim R, Sujan MSH, Islam MS, Ritu AH, Siddique MA Bin, Toma TY, et al. Prevalence and correlates of anxiety and depression in frontline healthcare workers treating people with COVID-19 in Bangladesh. BMC Psychiatry [Internet]. 2021 Dec 1 [cited 2021 Aug 22];21(1). Available from: /pmc/articles/PMC8146174/

11. Aly HM, Nemr NA, Kishk RM, Elsaid NMA bakr. Original research: Stress, anxiety and depression among healthcare workers facing COVID-19 pandemic in Egypt: a cross-sectional online-based study. BMJ Open [Internet]. 2021 Apr 30 [cited 2021 Aug 22];11(4). Available from: /pmc/articles/PMC8098284/

12. Nayak BS, Sahu PK, Ramsaroop K, Maharaj S, Mootoo W, Khan S, et al. Original research: Prevalence and factors associated with depression, anxiety and stress among healthcare workers of Trinidad and Tobago during COVID-19 pandemic: a cross-sectional study. BMJ Open [Internet]. 2021 Apr 13 [cited 2021 Aug 22];11(4). Available from: /pmc/articles/PMC8050873/

13. Basheti IA, Mhaidat QN, Mhaidat HN. Prevalence of anxiety and depression during COVID-19 pandemic among healthcare students in Jordan and its effect on their learning process: A national 
survey. PLoS One [Internet]. 2021 Apr 1 [cited 2021 Aug 22];16(4):e0249716. Available from: https://journals.plos.org/plosone/article?id=10.1371/journal.pone.0249716

14. Kong X, Zheng K, Tang M, Kong F, Zhou J, Diao L, et al. Prevalence and Factors Associated with Depression and Anxiety of Hospitalized Patients with COVID-19. medRxiv [Internet]. 2020 Apr 5 [cited 2021 Aug 22];2020.03.24.20043075. Available from:

https://www.medrxiv.org/content/10.1101/2020.03.24.20043075v2

15. Dai L-L, Wang X, Jiang T-C, Li P-F, Wang Y, Wu S-J, et al. Anxiety and depressive symptoms among COVID-19 patients in Jianghan Fangcang Shelter Hospital in Wuhan, China. PLoS One [Internet]. 2020 Aug 1 [cited 2021 Aug 22];15(8):e0238416. Available from: https://journals.plos.org/plosone/article? id $=10.1371 /$ journal.pone.0238416

16. Babatunde F, Yewande O, Charles U, Kehinde A, Omotayo A, Jaiyeola K, et al. Psychosocial health effects of Covid-19 infection on persons in treatment centers in Lagos, Nigeria. Brain, Behav Immun - Heal [Internet]. 2021 Jun 15 [cited 2021 Aug 22];16:100284-100284. Available from: https://europepmc.org/articles/PMC8205258

17. Ngasa NC, Ngasa SN, Armelle L, Tchouda S, Abanda C. Spirituality and other factors associated with COVID-19 Vaccine Acceptance amongst Healthcare Workers in Cameroon. J vaccines Vaccin [Internet]. 2021 Jul 13 [cited 2021 Aug 22]; Available from: https://www.researchsquare.com

18. Bjelland I, Dahl AA, Haug TT, Neckelmann D. The validity of the Hospital Anxiety and Depression Scale: An updated literature review. J Psychosom Res [Internet]. 2002 [cited 2021 Aug 22];52(2):69-77. Available from: https://pubmed.ncbi.nlm.nih.gov/11832252/

19. Saidi I, Koumeka PP, Batahar SA, Amro L. Factors associated with anxiety and depression among patients with Covid-19. Respir Med [Internet]. 2021 Sep 1 [cited 2021 Aug 22];186:106512. Available from: /pmc/articles/PMC8222859/

20. Mude W, Oguoma VM, Nyanhanda T, Mwanri L, Njue C. Racial disparities in COVID-19 pandemic cases, hospitalisations, and deaths: A systematic review and meta-analysis. J Glob Health [Internet]. 2021 [cited 2021 Aug 29];11:1-15. Available from: /pmc/articles/PMC8248751/

21. Doumas M, Patoulias D, Katsimardou A, Stavropoulos K, Imprialos K, Karagiannis A. COVID19 and increased mortality in African Americans: socioeconomic differences or does the renin angiotensin system also contribute? J Hum Hypertens 20203411 [Internet]. 2020 Jul 15 [cited 2021 Aug 29];34(11):764-7. Available from: https://www.nature.com/articles/s41371-020-0380-y

22. Nochaiwong S, Ruengorn C, Thavorn K, Hutton B, Awiphan R, Phosuya C, et al. Global prevalence of mental health issues among the general population during the coronavirus disease-2019 pandemic: a systematic review and meta-analysis. Sci Rep [Internet]. 2021 Dec 1 [cited 2021 Aug 29];11(1). Available from: https://pubmed.ncbi.nlm.nih.gov/33986414/ 
23. Wu T, Jia X, Shi H, Niu J, Yin X, Xie J, et al. Prevalence of mental health problems during the COVID19 pandemic: A systematic review and meta-analysis. J Affect Disord [Internet]. 2021 Feb 15 [cited 2021 Aug 22];281:91. Available from: /pmc/articles/PMC7710473/

24. Cheng SKW, Wong CW, Tsang J, Wong KC. Psychological distress and negative appraisals in survivors of severe acute respiratory syndrome (SARS). Psychol Med [Internet]. 2004 [cited 2021 Aug 29];34(7):1187-95. Available from: https://pubmed.ncbi.nlm.nih.gov/15697045/

25. Yang $X, Y u Y, X u$ J, Shu H, Xia J, Liu H, et al. Clinical course and outcomes of critically ill patients with SARS-CoV-2 pneumonia in Wuhan, China: a single-centered, retrospective, observational study. Lancet Respir Med [Internet]. 2020 May 1 [cited 2021 Aug 22];8(5):475-81. Available from: https://pubmed.ncbi.nlm.nih.gov/32105632/

26. Mazza MG, Lorenzo R De, Conte C, Poletti S, Vai B, Bollettini I, et al. Anxiety and depression in COVID-19 survivors: Role of inflammatory and clinical predictors. Brain Behav Immun [Internet]. 2020 Oct 1 [cited 2021 Aug 30];89:594. Available from: /pmc/articles/PMC7390748/

27. KY SK, R Bhat PK, Sorake CJ. Double trouble: a pandemic of obesity and COVID-19 [Internet]. Vol. 6, The Lancet Gastroenterology and Hepatology. Elsevier; 2021 [cited 2021 Aug 22]. p. 608. Available from: http://www.thelancet.com/article/S2468125321001904/fulltext

28. Rajkumar RP. Cross-National Variations in COVID-19 Mortality: The Role of Diet, Obesity and Depression. Dis 2021, Vol 9, Page 36 [Internet]. 2021 May 6 [cited 2021 Aug 22];9(2):36. Available from: https://www.mdpi.com/2079-9721/9/2/36/htm

\section{Figures}




\section{Frequency $(\mathrm{N}=59)$}

35

30

25

20

15

10

5

0

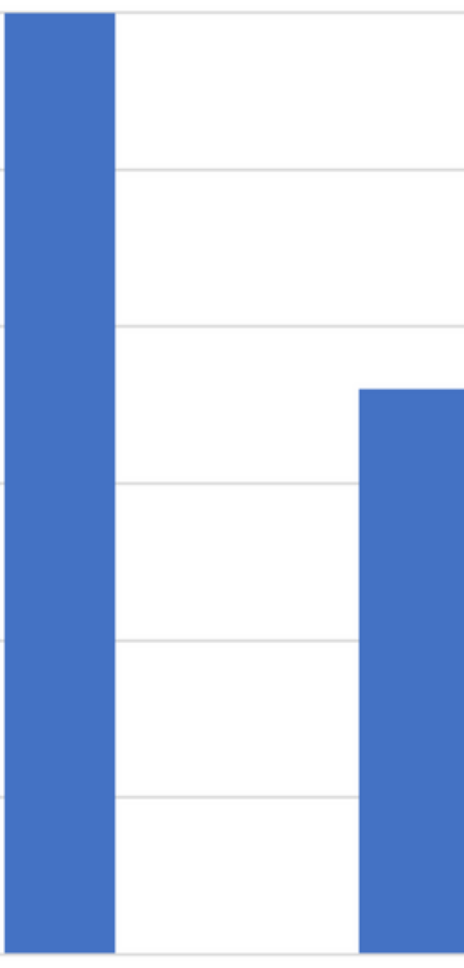

Hypertension

HIV
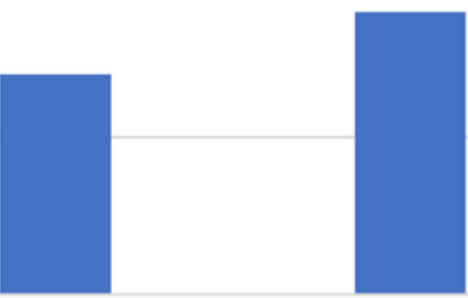

Renal Disease

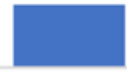

Others

\section{Figure 1}

Frequency of comorbidities in study population 


\section{PREVALENCE(\%) OF ANXIETY AND DEPRESSION, $\mathbf{N}=\mathbf{2 8 5}$}

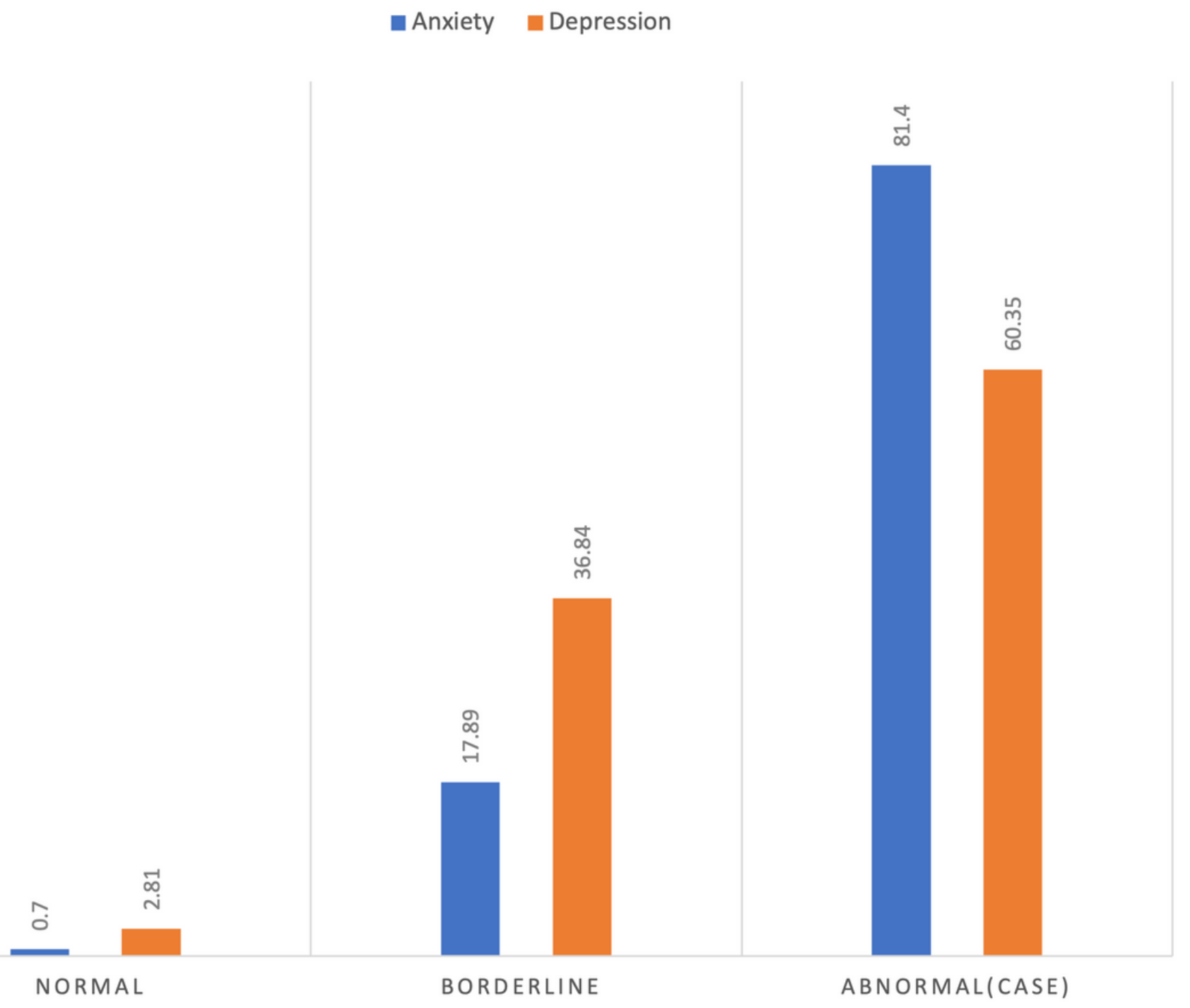

Figure 2

Prevalence of Depression and Anxiety among hospitalised COVID-19 patients 